\title{
EL TESTAMENTO Y EL RITO DE LA MUERTE: SEÑALES BURLESCAS Y PARÓDICAS DE CONTENIDO IDEOLÓGICO EN EL DESENLACE DEL QUIJOTE
}

\author{
LAST WILL AND TESTAMENT AND THE RITES OF \\ DEATH: BURLESQUE AND PARODIC EXPRESSIONS \\ OF IDEOLOGICAL CONTENT IN THE FINAL SCENE \\ OF DON QUIXOTE
}

\author{
John O'KuinghtTons Rodríguez \\ Universidade de São Paulo \\ Grupo de estudios Cervantes \\ johnochile@gmail.com
}

RESUMEN: En este artículo pretendo mostrar que en el episodio de la muerte de don Quijote hay acentos ideológicos de relativización de los poderes seglares y religiosos que se manifiestan mediante la redacción de un testamento de tenor burlesco y el guiño paródico dirigido a los ars moriendi. Asimismo, discuto la trascendencia que reviste la determinación de la muerte bajo el signo de la cordura o la locura para la validación de determinadas posturas ideológicas subyacentes en la novela.

Palabras clave: Miguel de Cervantes; Don Quijote de la Mancha; testamento; rito; muerte.

Abstract: This article aims to show that in the episode of don Quixote's death there are signs of a questioning of the religious and secular powers, in the elaboration of an ironic testament and in the expression of a burlesque view of the Ars moriendi. It also discusses the implications of understanding don Quixote's death as a sign of sanity or madness when determining certain ideological stances that underlie the novel.

Keywords: Miguel de Cervantes; Don Quijote de la Mancha; testament; rite; death.

Recepción: 16 de febrero de 2016; aceptación: 10 de enero de 2017. 


\section{INTRODUCCIÓN}

Como bien señala Rubio Árquez (2012), dada su condición de término, el último capítulo del Quijote original -que se inicia con la invocación del tema memento mori- es una pieza cuya interpretación está muy lejos de ser unánime o consensuada entre los críticos cervantinos. Buena parte de esta controversia consiste en el reconocimiento o la refutación de la curación mental efectiva del caballero, de donde se desprenden tales o cuales comprensiones de la cabalidad de la novela ${ }^{1}$.

El fin del caballero aparece prefigurado en las tempranas palabras del prólogo por intermedio del propio Cervantes, quien, visiblemente atenazado por la circulación de la imitación de Avellaneda, decide anular cualquier posibilidad de prolongación de su héroe mediante el recurso definitivo de su muerte. El encabezamiento del capítulo nos recuerda también el fin (De cómo don Quijote cayó malo, y del testamento que hizo, y su muerte) y nos adelanta dos particularidades: una que, a mi juicio, convoca relevantes intersticios ideológicos ${ }^{2}$, el testamento; y otra, según creo, su necesidad de confesión. Ambas operaciones se realizan en un ambiente sensible, de variadas connotaciones afectivas y de no menos angulares representaciones ideológicas que podemos entrever durante la agonía del hidalgo.

Antes de revisar estos aspectos, y para aquilatar la calidad del ánimo que abruma al protagonista y que incide directamente en su postración, conviene recordar cómo se da la entrada de los personajes en la aldea de donde son oriundos. Lo primero en emerger, aunque ya sin el tenor represivo de escenas anteriores, es la riña de dos muchachos, uno de los cuales, a propósito de una jaula de grillos, pronuncia la frase "no la has de ver en todos los días de tu vida", que en el entendimiento del hidalgo se significa como una suerte de mal agüero sobre Dulcinea,

1 Sobre este punto, verbigracia, Margit Frenk (2013) ha señalado que el juicio sobre la condición de la muerte del caballero-hidalgo comporta un halo de notada imprecisión: "Pienso que Cervantes no sería Cervantes si en ese final de su obra hubiera renunciado a la ambigüedad, si no hubiera proyectado sobre la afirmación de la cordura de su héroe un gran signo de interrogación" (p. 52).

${ }^{2}$ Por razones operativas, en este trabajo utilizo el término ideología (cuyo uso es bastante posterior a la época de Cervantes) según la acepción de VAN Dijk (1999, p. 21): "base de representaciones sociales compartidas por los miembros de un grupo". Esta definición esencial da perfecta cuenta del problema que me propongo tratar. 
a quien supuestamente no habrá de volver a ver. El episodio se asoma como una última negación de las supersticiones vocalizada por el propio Sancho, a estas alturas un hombre que ha sabido aprovechar las enseñanzas que le han dejado los fructíferos diálogos con su amo a lo largo de las aventuras compartidas:

Y si no me acuerdo mal, he oído decir al cura de nuestro pueblo que no es de personas cristianas ni discretas mirar en estas niñerías; y aun vuesa merced mismo me lo dijo los días pasados, dándome a entender que eran tontos todos aquellos cristianos que miraban en agüeros (II, 73, p. 883).

Esta respuesta a la idea que don Quijote se ha hecho del asunto actúa en cierto modo como preámbulo de la escena final, en la que habrá de reivindicarse, al menos de forma declarada, la conveniencia de la razón como ordenadora del mundo y garante del equilibrio emocional. En II, 58 nos encontramos con este elocuente juicio:

Tú dices bien, Sancho -dijo don Quijote-, pero has de advertir que no todos los tiempos son unos, ni corren de una misma suerte, y esto que el vulgo suele llamar comúnmente agüeros, que no se fundan sobre natural razón alguna, del que es discreto han de ser tenidos y juzgar por buenos acontecimientos (p. 797).

Pero esta celebración de la razón no se realiza sino hasta que el hidalgo da muestras precisamente de lo contrario, cuando reformula su programa caballeresco ataviándolo de una forma inesperada, pero cercana a los parámetros de la literatura por su vínculo a un género continuamente aludido: el ejercicio pastoril. La misma locura permanece, sólo cambia el tema, lo cual irónicamente relativiza la solidez de su proyecto como una suerte de prólogo de lo que ocurrirá con su conciencia identitaria durante su agonía. El ama le ruega que abandone esos delirios usando tres demandas que resumen la percepción social de la integridad de un hidalgo: cuidado de la hacienda, confesión y ayuda a los pobres ${ }^{3}$. Ante estas intervenciones, don

3 Sobre estas solicitudes, Alfonso Martín Jiménez (2014) entiende que son remedo de las preocupaciones expuestas por Mosén Valentín en el Quijote émulo, como se advierte en este pasaje: "Por tanto, señor Quijada, por la pasión que Dios pasó, le ruego que vuelva sobre sí y deje esta locura en que anda, volviéndose a su tierra; y pues me dice Sancho que vuesa merced tiene razonablemente hacienda, gástela en servicio de Dios y en hacer bien 
Quijote responde confirmando su conciencia sobre los deberes que le caben: la afirmación "yo sé bien lo que me cumple" (II, 73, p. 886) opera como una variación de la frágil conciencia identitaria que manifiesta muy tempranamente en la primera salida. El "yo sé quién soy" del capítulo 5 conlleva una notoria ambigüedad sobre la cuestión de la identidad recién asumida y proyecta sobre el resto de la obra la posibilidad de que esta conciencia vaya redundando gradualmente en la reversibilidad. Si entendemos ambas afirmaciones como variantes articuladas de un mismo problema, entonces es lícito sospechar que una nueva afirmación identitaria de este tipo debería ser tomada con cautela. Lo que importa subrayar es que sea cual sea el proyecto asumido, el manchego mantendrá como eje de sus bases axiológicas la solidaridad y el servicio público: “...tened por cierto que, ahora sea caballero andante o pastor por andar, no dejaré siempre de acudir a lo que hubiéredes menester, como lo veréis por la obra" (II, 73, p. 886).

Según el parecer del médico que lo asiste, la repentina fiebre que lo afecta poco después de llegar es consecuencia de la melancolía y de las penurias pasadas. Lo ciertamente inesperado, tanto para personajes como para lectores, es la aparente y súbita recuperación de la cordura, confirmada por la invocación divina. Don Quijote, que durante sus andanzas prescindió de este testigo celestial, ahora proclama la intercesión de Dios como propiciador de su mejoría. No bien alude a este hecho imprevisible cuando se ocupa de otro, la refutación de los libros de caballerías, a los que acusa con los mismos términos que antes utilizaron sus principales detractores. Con ello, el hidalgo parece alinearse con el discurso retórico tan explícitamente defendido por el cura y el canónigo de Toledo en otras ocasiones. Acto seguido solicita la comparecencia del cura, Sansón Carrasco y maese Nicolás, para confesarse y hacer su testamento y la proclamación de su asumida identidad: “...ya yo no soy don Quijote de La Mancha, sino Alonso Quijano, a quien mis

a pobres, confesando y comulgando a menudo, oyendo cada día su misa, visitando enfermos, leyendo libros devotos y conversando con gente honrada..." (Fernández de Avellaneda 2005, p. 309). Otro de los guiños hechos a Avellaneda, e identificado por Jiménez, es la respuesta que Sancho da a su esposa en cuanto a su desempeño como gobernador: "Dineros traigo, que es lo que importa, ganados por mi industria y sin daño de nadie" (CERVANTES, p. 884). Para Jiménez, en esta intervención, Cervantes alude a la bajeza de su rival por tratar de sacar provecho económico de su invención. 
costumbres me dieron renombre de Bueno" (II, 74, p. 888). La primera sospecha de que esta recuperación debe tomarse con cautela proviene de los propios personajes, que no sólo no dan crédito a la afirmación, sino que refuerzan la mitología caballeresca que tanto intentaron erradicar. A lo largo de todo este episodio los personajes mantendrán una conducta ambivalente, ya que si por un lado desacreditan la cordura, por otro tienden a admitirla, pues recelan de que lo repentino de su logro pueda ser síntoma de la muerte inminente: “...una de las señales por donde conjeturaron se moría fue el haber vuelto con tanta facilidad de loco a cuerdo" (II, 74, p. 889). Son precisamente los dos representantes de los grandes poderes (religioso y secular) quienes dan cierto margen de duda al equilibrio recobrado. Por una parte, como veremos, el cura compara sutilmente el estado del hidalgo con el del caballero Tirant. Por otra, el escribano declara abiertamente y sin cortapisas que el héroe ha muerto como adalid de la caballería: "Hallóse el escribano presente, y dijo que nunca había leído en ningún libro de caballerías que algún caballero andante hubiese muerto en su lecho tan sosegadamente y tan cristiano como don Quijote..." (II, 74, p. 891).

\section{LA CONFESIÓN}

Por principio institucional, la confesión del hidalgo se realiza sin otro testigo que el cura, de modo que ignoramos cuáles habrán sido los pecados reconocidos y tratados a la luz del sacramento. Sólo en este momento se admite públicamente la recuperación del juicio: "Verdaderamente se muere, y verdaderamente está cuerdo Alonso Quijano el Bueno ${ }^{4}$; bien podemos entrar para que haga su testamento" (II, 74, p. 889). Tal reconocimiento debía ser fehaciente, pues se autoriza la redacción

${ }^{4}$ El cognomen, razona MARTín Jiménez (p. 406), parece ser respuesta al modo como Avellaneda alude a su respectivo personaje en la carta remitida por Aldonza Lorenzo: "Martín Quijada, el mentecapto". Este atrevimiento, sigue Martín Jiménez, habría dado pie a que Cervantes replicara con una afirmación de la dignidad del caballero mediante una expresión ensalzadora: “...el sobrenombre de «el Bueno" ya no solo atañe a la calidad literaria del verdadero don Quijote, sino también a su bonhomía. Los personajes de 1614 no sentían un verdadero aprecio por don Quijote (como tampoco lo mostraba su autor), sino que solo pretendían burlarse de él, y el mismo Sancho acaba por abandonarlo a su suerte en la casa de orates de Toledo". 
del testamento, para el cual es condición prevalente la absoluta lucidez de su gestor.

Según James Iffland (1999), estas dos expresiones de la voluntad -confesión y testamento- son índices de que Cervantes quiso que su personaje se alineara, al menos mediante el reconocimiento, con los grandes poderes que gobiernan una matriz ideológica: el secular y el religioso. La solicitud del escribano revela que el personaje, además de la Iglesia, dice Iffland, "quiere arreglárselas con el Estado" (p. 553). Esta petición, explica el estudioso, viene a operar como una suerte de confesión seglar, cuya finalidad sería la reinserción definitiva en el ámbito ideológico dominante. Con ambos actos conscientes, el hidalgo estaría haciendo una valoración pública y documentada de estos poderes, los mismos contra los que, siendo caballero, propinó diversas ironías y descalificaciones o cuya importancia sobre los aconteceres sociales tan abiertamente desestimó. De ser así, con esta recuperación del juicio, el caballero no sólo refutaría el género literario que nutrió su fantasía, sino que exculparía ideológicamente a los poderes de los que antes receló. Desde esta perspectiva, la novela acabaría legitimando de alguna forma las expresiones ideológicas instaladas en el ejercicio del poder. No obstante, hay algunos indicios que nos permiten barruntar un orden de cosas más complejo y que abriría espacio para la reafirmación contestataria del caballero mediante la ejecución de una parodia ulterior que, evidentemente, torna feble la eventual reconquista de la lucidez. Esta parodia tendría asidero en la elaboración del propio testamento y en el rito de muerte que domina la escena. Antes de revisarlos por separado, examinemos las connotaciones religiosas que abrigan la confesión y sus efectos.

De inicio, digamos que quien solicita la confesión no puede ser don Quijote, pues -al decir de Iffland (1999)- bajo la piel de caballero andante nunca se comportó como católico practicante. Ello validaría, al menos en un primer acercamiento, la recuperación del juicio. El sacramento, indica Carlo Collo (1995), tiene como finalidad la paz de conciencia y el consuelo del alma. La etimología de la palabra se remonta al latín confessio, que significa 'declaración o reconocimiento público', y en su aplicación eclesial busca fundamentalmente el arrepentimiento interior, no una exposición de falencias ni una acusación. El Concilio de Trento ratificó la necesidad de confesión y determinó que para lograr la absolución plena por parte del 
confesor, el penitente debía pronunciarse conscientemente sobre los llamados pecados mortales. Una de las características del sacramento es que, además de secreto, puro y discreto, debe ser auricular. Asimismo, una de las faltas que prescribían el acto de confesión, y que muy probablemente fue la que en su supuesta sanidad Alonso Quijano expuso al cura, es la de perjurio hecho con daño del próximo. El sacramento, como bien cabe a la organización eclesiástica, seguía una rigurosa prescripción judicial que definía condiciones, penalidades para los omisos y disposiciones generales de regulación. José Rodríguez Molina (2008), por ejemplo, recuerda que, conforme las Constituciones sinodales de Sevilla de 1586, los curas debían visitar a los enfermos para incitarlos a la confesión y a la elaboración de sus testamentos, algo que el cura cervantino ciertamente no desconoce. Las sanciones preveían publicación de nombres en las iglesias, prisión y excomunión. Por lo demás, la elaboración de testamentos explica el carácter judicial con que estas regulaciones pretendían movilizar las conciencias de los creyentes. Como señala Rodríguez Molina, cuando pasados los treinta días de una acusación un omiso no daba signos de contrición, se convocaba "el auxilio del brazo secular para que los prendan y no se den sueltos, ni en fiado, hasta tanto que ayan confessado y cumplido con el mandamiento de la Iglesia”. Estos controles asumían tenacidades febriles, como una disposición del hospital de iglesia de Santa Ana de Granada, donde los enfermos sólo podían ingresar previo acto de confesión. La omisión del sacramento acarreaba la negación del servicio médico.

El Concilio Lateranense IV trajo dos importantes determinaciones que permitieron la consagración del sacramento en los parámetros que hoy conocemos: la obligación de la confesión anual y el carácter secreto de la confesión. Su condición auricular le permite reforzarse como émulo de las prácticas judiciales, como se muestra en las siguientes equiparaciones: juez/ cura, pecado/ delito, condena/ penitencia ${ }^{5}$. Sobre este punto, Ricardo Franco (1972) aclara lo siguiente:

Digamos que, en cualquier hipótesis, el juicio sacramental es solamente análogo con cualquier otro juicio, pues aquí no se trata de condenar al criminal, sino precisamente de absolverlo, de hacerlo realmente inocente, no sólo de declararlo inocente. Aunque

${ }^{5}$ El Concilio de Trento sellará el sacramento como práctica de orden divino. 
se diferencie en esto, coincide con cualquier otro juicio en que la sentencia es eficaz. Muchos teólogos de Trento afirman que la penitencia es judicial porque "los sacerdotes... verdaderamente absuelven" (p. 5).

Como se advierte en la cita, la confesión sacramental católica se aparta de la judicial en que busca purificar la conciencia del pecador. La penitencia, en consecuencia, es una suerte de castigo que atiende al mejoramiento y no a la represión del individuo.

El conjunto somero de propiedades que he revisado del sacramento (voluntario y espontáneo -esto último condicionado, según se ha visto, a las cortapisas impuestas por la corporación eclesial-, purificador e integrador) permite comprender, efectivamente, la voluntad de don Quijote como un acto fundado en el arrepentimiento, a la vez que provocado, al menos en apariencia, por el anhelo de reintegrarse al eje social y de reconocer la legitimidad y poder de la institución que lo administra. Ello, no obstante, contradice plenamente la conducta que el caballero ha tenido a lo largo de su militancia andante. Según adelantamos, como indica Iffland (1999), don Quijote ha obliterado continuamente los ritos de la Iglesia:

Nunca escucha un sermón, nunca va a misa, no comulga, usa un rosario hecho con la parte inferior de su camisa, se encomienda a su dama y no a Dios, o antes que a Dios, o simultáneamente, o sin acordarse de Él, práctica cuya heterodoxia se comenta abiertamente en la $1^{\mathrm{a}}$ parte y que fue uno de los motivos que llevaron a los ideólogos de la Contrarreforma a atacar los libros de caballerías (p. 207).

Es comprensible atribuir las omisiones rituales a la naturaleza nómada de la orden caballeresca, ciertamente, pero no parece serlo su falta constante de invocación divina. Por tanto, es posible suponer que esta negligencia bien podría haber formado parte de los asuntos tratados en la confesión que hizo el caballero-hidalgo para aligerar su conciencia.

\section{EL TESTAMENTO}

Hecha la confesión, la siguiente acción, volitiva y presuntamente razonada, es la realización del testamento. La articulación 
de ambas tramitaciones no es fortuita. Desde el punto de vista del significado vertebral de la muerte -la renuncia absoluta a la materia-, el confesor y el escribano funcionan como el eje de esta premisa. Traigo a colación un oportuno pasaje de Ariès (2013, p. 261):

Um autor piedoso de 1736 escreve no primeiro capítulo de um Méthode chrétienne pour finir saintement sa vie, isto é, uma arte de bem-morrer no século XVII: "¿Que faz um doente que se vê em perigo de morte? Manda chamar um confessor e um notário". Um e outro são igualmente necessários: eis o que parece extraordinário para um manual de bem-morrer que ensina o desapego e o desprezo do mundo. Ele explica: "Um confessor para pôr em orden os negócios da sua consciência, um notário para fazer o testamento".

A lo anterior añade el siguiente complemento: "O testamento foi, por tanto, o meio religioso e quase sacramental de ganhar as aeterna sem perder completamente as temporalia, ou seja, de associar as riquezas à obra de salvação" (p. 253). Se colige, pues, que por venir impuesto desde la Iglesia, el testamento poseía un tenor religioso: quien moría sin testar no podía ser enterrado en iglesia o cementerio.

Bajo este orden de cosas, la disposición a testar del hidalgo $^{6}$, que funciona como un saldo de cuentas y un apaciguador de conciencia, demuestra su pública preocupación por la condición de quienes le son más cercanos. Como señalé anteriormente, la redacción de un testamento presume la absoluta sanidad mental de su ejecutor e implica reconocimiento de la potestad del Estado sobre los asuntos económicos y legales ${ }^{7}$. El documento del hidalgo consta de cuatro ítems que, a saber, estipulan:

${ }^{6}$ No es inoportuno recordar que, en su condición de hidalgo y, por tanto, como poseedor de bienes materiales, algo ajeno a la inmensa mayoría de la población, Alonso Quijano estaba facultado para emitir un documento de este tipo.

${ }^{7}$ ArIÈs (2013) señala que el testamento es trasunto de ritos anteriores: "O testamento reproduz por escrito os ritos orais da morte de outrora. Fazendo-os entrar no mundo da escrita e do direito, retira um pouco do seu caráter litúrgico, coletivo, habitual, poderia quase dizer folclórico. Personaliza-se. Mas não completamente. $\mathrm{O}$ velho espírito dos ritos orais não desapareceu" (p. 268). 
1. Dinero resultante de las cuentas habidas entre don Quijote y Sancho Panza para beneficio del escudero.

2. La hacienda íntegra para Antonia Quijana, la sobrina. Para el ama, salario por el tiempo de su servicio más veinte ducados para un vestido.

3. Voluntad de que si la sobrina desea casarse lo haga con un hombre que ignore la existencia de los libros de caballerías. Expropiación de los bienes en caso de que esta condición sea incumplida.

4. Petición de perdón a Avellaneda por haberle inspirado la ejecución de su libro.

Como ha advertido Iffland (1999), durante su militancia caballeresca, don Quijote no pareció convenir con las prácticas, ejercicios y disposiciones del poder estatal. Ahora, con lucidez y perspectiva, procede del modo opuesto. Según el crítico, que no descree de la sanidad del hidalgo, el regreso a la lucidez es el recurso narrativo final que Cervantes adoptó para distanciarse categóricamente de Avellaneda y el determinante para la comprensión de la novela, porque gracias a él "define, evalúa y califica todo su proyecto ideológico anterior” (p. 551). Al declarar "...ya me son odiosas todas las historias profanas del andante caballería..." (II, 74, p. 888) estaría legitimando con un solo adjetivo (profanas) la posición eclesiástica sobre el tema y, más tarde, el poder del Estado vía el testamento. A diferencia de Avellaneda, sigue Iffland, Cervantes parece avizorar un final más digno del que le dio su contrincante. De ahí la muerte del héroe, que narrativamente busca la oclusión categórica de cualquier posible continuidad, tal como se había anunciado en el segundo prólogo: “...en ella [la Segunda parte] te doy a don Quijote dilatado, y, finalmente, muerto y sepultado, porque ninguno se atreva a levantarle nuevos testimonios..." (p. 445), lo cual se replica en las páginas finales en los siguientes términos: “...y que el tal testimonio pedía para quitar la ocasión de que algún otro autor que Cide Hamete Benengeli le resucitase falsamente, y hiciese inacabables historias de sus hazañas" (II, 74, p. 891).

La gravitación de Avellaneda es evidente, y es probable que, de no haber existido el continuador, la ficción original no habría concluido del modo en que lo hace. A mi entender, las inserciones finales justifican la sospecha de que el desenlace habría tomado otros derroteros: 
Para mí sola [declara la pluma] nació don Quijote, y yo para él; él supo obrar y yo escribir, solos los dos somos para en uno, a despecho y pesar del escritor fingido y tordesillesco que se atrevió, o se ha de atrever, a escribir con pluma de avestruz grosera y mal adeliñada las hazañas de mi valeroso caballero, porque no es carga de sus hombros ni asunto de su resfriado ingenio; a quien advertirás, si acaso llegas a conocerle, que deje reposar en la sepultura los cansados y ya podridos huesos de don Quijote, y no le quiera llevar, contra todos los fueros de la muerte, a Castilla la Vieja, haciéndole salir de la fuesa donde real y verdaderamente yace tendido de largo a largo, imposibilitado de hacer tercera jornada y salida nueva... (II, 74, p. 892).

La muerte del héroe aparece refrendada por la estima y el encomio que de él y de su valor hacen sus parientes y amigos. No obstante, junto con este realce de la dignidad extraviada por completo en la versión del epígono, se consagra ideológicamente la base de creencias que han venido defendiendo sus cercanos mediante el regreso territorial del hidalgo. Esta conclusión -que podría convencernos de la arrepentida y consciente aceptación de las instancias ideológicas del poder por parte del hidalgo- amerita una revisión.

Antes que todo, conviene señalar que, como razona Rubio Árquez (2012), el testamento quijotesco -o quijanesco- parece obedecer a una reescritura deliberada y paródica de esa forma judicial, que no comparece únicamente en el cierre de la obra, sino que transita por el decurso de toda ella sin que llegue a determinarse fehacientemente su unicidad. En la época de Cervantes, los testamentos conocían un dilatado ejercicio; sus numerosos ejemplos dan cuenta de una expresión que, como indica Rubio Árquez, poseía formalidades suficientemente definidas que permiten asignarle estatura de género. El estudioso sugiere que es muy probable que Cervantes haya tenido en cuenta no sólo estos documentos, sino también sus derivaciones burlescas, que por aquel entonces eran de frecuente circulación. Títulos como Testamento de un lechón o Testamento del picaro pobre, que podían ir escritos tanto en prosa como en verso, anuncian su intención y origen. Eran de carácter fundamentalmente popular, pero también llegaban a manos privilegiadas y a lectores como el propio Cervantes. Como declara Rubio Árquez (2012), es muy difícil que

...aquel que se declaraba "aficionado a leer aunque sean los papeles rotos de las calles" pudiera no conocer todo este caudal de 
literatura popular que circulaba por calles y palacios antes, durante y después de la redacción de su magna obra y que, conociéndola, no haya caído en la literaria tentación de utilizarla-textual, ideológica, retóricamente- en la composición del último capítulo de su obra, sobre todo porque el tono de su obra y, en algunos aspectos, el de los testamentos burlescos son afines (pp. 306-307).

Comentamos antes que no es evidente que el testamento a que se alude en diversos momentos de la novela implique unidad de modo fehaciente. El tema del testamento aparece de forma episódica pero recurrente y con diferentes motivaciones en la ficción. Figura, por ejemplo, cuando se trata del sueldo prometido al escudero. En el episodio de los batanes, don Quijote dice a Sancho que no se preocupe por su salario, "porque él había dejado hecho testamento antes que saliera de su lugar..." (I, 20, p. 151). No será ésta la única ocasión en que aludirá a la realidad de ese documento. En episodios posteriores volverá a mencionarlo con una seguridad que no deja lugar a dudas: “...en mi testamento, que ya está hecho, dejo declarado lo que se le ha de dar, no conforme a sus muchos y buenos servicios, sino a la posibilidad mía” (I, 46, p. 393).

Creo que la existencia de dicho registro es cuestionable por dos razones medulares: $a$ ) el modo negligente como don Quijote ha tratado su hacienda; $b$ ) el modo furtivo y apresurado con que ambos personajes dejaron la aldea. Esta supuesta mentira, evalúa Rubio Árquez (2012), no condice con las premisas axiológicas que orientan la militancia del caballero. Más probable parece ser que este prototestamento haya sido una promesa destinada a calmar las impaciencias e incertidumbres pecuniarias del escudero, cuyo cumplimiento tendría en vista, tal y como acontece en el desenlace. Esta hipótesis, empero, colide con una posterior afirmación del hidalgo en la que irrumpe un comentario inesperado:

...si yo ahora te he señalado a ti en el testamento cerrado que dejé en mi casa, fue por lo que podía suceder, que aún no sé cómo prueba en estos tan calamitosos tiempos nuestros la caballería, y no querría que por pocas cosas penase mi ánima en el otro mundo (I, 20, p. 154).

Esta aserción suscita dos justificadas interrogantes: ¿cuál ha sido el verdadero objetivo del supuesto testamento?; ¿fue el testa- 
mento del desenlace una reformulación del prototestamento? Rubio Árquez (2012) piensa que con esta última afirmación, transcrita arriba, el hidalgo, más que mentirle a Sancho, quiere aclarar que su intención ha sido espiritual y precautoria, lo cual lo pondría en la línea ideológica jurídico-religiosa que más tarde en su lecho de muerte habría de consagrar, al menos en apariencia. Pese al reconocimiento del hidalgo de una paga salarial conforme a sus recursos, en la Segunda parte resurge el problema de cómo se ha de remunerar efectivamente al escudero. En II, 46, don Quijote deja muy en claro que, según sus lecturas, los escuderos ofician por merced, no por contante y sonante, y por consecuencia con este hábito presenta a Sancho un ultimátum: o lo sigue bajo esta condición o desiste. El escudero justificará que los emolumentos tan impacientemente demandados han sido exigencia de su esposa. Al cabo, y aunque no se lo diga explícitamente, ambos llegan al acuerdo de las mercedes. El prototestamento, que según se ha visto preveía un pago salarial acorde a las posibilidades del hidalgo, habría, pues, de reformular la naturaleza de la remuneración de los servicios del escudero, conforme la solicitud del mismo Sancho: “...y así, no hay más que hacer, sino que vuestra merced ordene su testamento con su codicilo, en modo que no se pueda revolcar, y pongámonos en camino...". El acuerdo se sella con un gesto de informal aprobación: "Finalmente, don Quijote y Sancho se abrazaron y quedaron amigos..." (II, 7, p. 488), pero aun cuando queda así pactada, la relación de trabajo no perderá su naturaleza pecuniaria, como enseñan estas posteriores increpaciones del caballero contra su servidor:

Y si tanto deseáis volveros a vuestra casa con vuestra mujer e hijos, no permita Dios que yo os lo impida; dineros tenéis míos: mirad cuánto ha que esta tercera vez salimos de nuestro pueblo, y mirad lo que podéis y debéis ganar cada mes, y pagaos de vuestra mano (II, 28, p. 621).

No obstante todo lo anterior, don Quijote sabe muy bien que los caballeros andantes, a excepción de Tirant, no suelen testar. De ahí que la alusión a este prototestamento esté quizás condicionada más a un aquietador de conciencia -social y trascendental- que a una evidencia constatable. 
TESTAMENTO, CORDURA E IDENTIDAD

La alusión al testamento como instancia judicial fehaciente y como señal de verosimilitud narrativa es uno de los fundamentos que permiten sospechar de la efectiva recuperación del juicio de Alonso Quijano. En su epílogo, recordemos, Alonso Quijano duerme en su cama, testa y muere. El cura que lo confiesa celebra la lucidez del moribundo y autoriza la redacción del documento. No obstante, conviene cifrar que esta misma tríada de acciones (dormir en la cama, testar y morir) fue enunciada por el propio cura como valoración de la naturaleza verosímil de Tirant lo Blanc durante el escrutinio:

Dígoos verdad, señor compadre, que por su estilo es este el mejor libro del mundo: aquí comen los caballeros, y duermen y mueren en sus camas, y hacen testamento antes de su muerte, con estas cosas de que todos los demás libros de este género carecen (I, 6, p. 58).

Evidentemente no es el personaje quien ofrece esta simetría entre ambos momentos de la ficción, sino el narrador, que parece hacernos un guiño para que no perdamos de vista la naturaleza caballeresca que pervive en el hidalgo. Tal guiño precede a la confección del testamento, lo que nos induce a pensar que la condición identitaria del testador no debería ratificarse de un modo tan taxativo como lo ha hecho el cura. Dicho de otro modo, el hidalgo que testa parece avenirse más con la figura del caballero Tirant que con la del juicioso vecino que todos aspiraban a encontrar.

Si el pedido de confesión hecho por el hidalgo parecía ser el reconocimiento del poder eclesial, se esperaría, en consecuencia, que en el testamento constaran las alusiones al poder divino y a sus ministros como parte integrante de las formalidades del género. Sin embargo, no es lo que encontramos. El motivo puede hallarse en el modelo paródico del testamento burlesco, que amputaba deliberadamente estas menciones como parte del juego lúdico. Pero no es menos posible que, adjunta a esta medida retórica, exista la motivación de relativizar la incumbencia de la Iglesia. De ser así, la conducta del hidalgo sería coherente y consecuente con el comportamiento omiso que ha tenido con ésta por todo lo ancho de su devenir aventurero. 
Por lo mismo, es posible barruntar que la publicitada recuperación mental no haya sido más que una ironía narrativa destinada a morigerar las afirmaciones que, en apariencia, el discurso del moribundo defiende. Así, el supuesto reconocimiento de las instancias ideológicas (iglesia/ estado) y sus expresiones formales (confesión/ testamento) no sería más que especular o ilusorio. La sospecha no es fortuita, y se basa en el mismo aparato ficcional. Tras la muerte del hidalgo, el escribano afirma que "nunca había leído en ningún libro de caballerías que algún caballero andante hubiese muerto en su lecho tan sosegadamente y tan cristiano como don Quijote" (II, 74, p. 891). Lo que no huelga destacar es el hecho de que el escribano, como bien recuerda Rubio Árquez (2012), no ejerce una función baladí, sino de alto vicario, por cuanto representa nada menos que la legalidad vigente. El resto de los personajes tampoco da muestras de convencimiento de la sanidad recuperada. A ello hay que agregar que ni siquiera el propio narrador se abstiene de imprimir una huella de sospecha, pues insiste en referirse al doliente no con su nombre civil, sino con su mote literario: "Los de hasta aquí -replicó don Quijote-, que han sido verdaderos en mi daño"; "Miráronse unos a otros, admirados de las razones de don Quijote"; “...después de haber hecho la cabeza del testamento, y ordenado su alma don Quijote" (II, 74, p. 889); “...llegó el último de don Quijote, después de recibidos todos los sacramentos...” (II, 74, p. 891).

En este orden de cosas, el testamento final, a diferencia del que hemos llamado prototestamento, no sólo tiene una función apaciguadora de conciencia y de justicia, sino también narratológica, pues con él se clausuran definitivamente las posibilidades de que la novela tenga alguna continuación, tal y como se nos adelantó en el segundo prólogo. Presume Rubio Árquez (2012, p. 320) que la rapidez con que se elabora el documento sugiere una recreación burlesca del género. De la cabecera sólo se dice que fue realizada -"Entró el escribano con los demás, y, después de haber hecho la cabeza del testamento y ordenado su alma don Quijote"-, para ingresar de lleno en las disposiciones centrales de la herencia, que no sólo dan cuenta de los bienes que entran en juego, sino que "constituyen, caracterizan y delimitan" la personalidad del testador en este tipo de recreaciones, al punto de que al leer el tenor de las mandas percibimos que se emparentan más con don Quijote que con Alonso Quijano. La segunda manda (herencia de la sobrina y salario 
del ama) y la tercera (condiciones para el eventual casamiento de la sobrina) son las únicas que parecen proferidas por Alonso Quijano. El tono irónico de aquélla es evidente, pues, aparte de que el pago al ama prevé singular atraso, el dinero complementario prometido tiene un fin muy específico y prosaico. La tercera, en cambio, entra directamente en el absurdo, pues obliga a la sobrina a casarse según la inconcebible presunción de que se desconozcan los libros de caballerías ${ }^{8}$.

Las otras mandas guardan relación con don Quijote y sus antecedentes caballerescos, sea en la forma de deudas pecuniarias que derivan del contrato de palabra entre don Quijote y Sancho, sea en la irónica valoración de la imitación de Avellaneda. Con esta última manda se solicita el perdón del epígono por haberle incitado a emprender su libro ${ }^{9}$. Los disparates a que se alude -“...perdone la ocasión que sin yo pensarlo le di de haber escrito tantos y tan grandes disparates como en ella escribe" (II, 74, p. 891)- fueron obras de don Quijote, y aunque la desvalorización de éstas pueda venir de Alonso Quijano, el arrepentimiento es de quien las llevó a cabo. Por lo tanto, la manda compete al mundo de las aventuras acontecidas. En consecuencia, como ha enseñado Rubio Árquez (2012, p. 321), "las mandas delimitan perfectamente al personaje", lo caracterizan a tal punto que sólo pueden haber sido proferidas por el caballero y no por el austero vecino que el moribundo afirma ser.

\section{EL ARTE DEL BUEN MORIR}

Una vez revisada la ocurrencia de las consagraciones institucionales -confesión y testamento- conviene considerar el ambien-

${ }^{8}$ La novela acaba con un guiño a ese conocimiento, esta vez con palabras de Cide Hamete, quien declara con nostálgica conclusión: “...yo quedaré satisfecho y ufano de haber sido el primero que gozó el fruto de sus escritos enteramente, como deseaba, pues no ha sido otro mi deseo que poner en aborrecimiento de los hombres las fingidas y disparatadas historias de los libros de caballerías, que, por las de mi verdadero don Quijote, van ya tropezando, y han de caer del todo, sin duda alguna. Vale" (II, 74, p. 893). Como se ve en este cierre, Cide Hamete llama verdadero a su caballero. No me parece improbable que esto haya servido de acicate para que una buena parte de la crítica cervantina apodara de falso el símil de Avellaneda.

${ }^{9}$ Según Ariès (2013), entre los ritos de la muerte, el moribundo medieval debía pedir el perdón de los compañeros, despedirse y encomendarlos a Dios. 
te en que se suscitan la agonía y el posterior deceso del hidalgo. De inicio subrayemos que todo acontece en un espacio cerrado, ocupado por parientes y amigos, con predominio, no absoluto, de un estado de ánimo compungido. Podemos imaginar el lecho de muerte situado en el centro de la habitación, en donde cada personaje parece representar un papel definido, como si se tratara de un guión teatral en que la muerte es el clímax de un rito fúnebre prefigurado. Philippe Ariès (2013) recuerda que en la literatura caballeresca los héroes no morían de manera traicionera, sino reglamentada, por lo cual se les daba oportunidad de percibir no sólo su fin, sino también el tiempo que les restaba. En tales personajes, agrega, eran comunes los desmayos, y don Quijote es precisamente acometido por una serie de vahídos ("se desmayaba muy a menudo", II, 74, p. 891) que va prologando, además de su desenlace físico, su conexión con los agonistas literarios que emuló durante sus andanzas. En lugar de una muerte abrupta o solitaria, que habría sido indigna para un caballero andante, Cervantes nos presenta un espacio en que todo ha sido dispuesto para que el deceso ocurra en estado de sosiego, de consagración espiritual y de empatía por parte de sus seres más cercanos ${ }^{10}$.

Este cuadro de sentida placidez y de explícitos preparativos no resulta fortuito si se conjetura sobre la posibilidad de que en su composición hayan gravitado los requisitos listados en los Ars moriendi o Arte de bien morir. Como se sabe, estos manuales pretendían guiar al moribundo cristiano hacia una muerte aligerada de culpas y esperanzada en la paz eterna. Asimismo, estos textos preveían un conjunto de condicionamientos para alcanzar la salvación, como se advierte en este pasaje:

Por ende, ante de todas cosas, sea inducido e amonestado el enfermo a aquellas cosas con que aya e alcançe la salud de la ánima, e son necesarias para salvación. Primeramente, que crea assí como buen cristiano los artículos de la fe, segund que la Santa Madre Iglesia los tiene e cree. Segundo, que sea alegre porque muere en la fe de Nuestro Señor IhesuChristo en la obediencia e unidad de su Santa Iglesia. Tercero, que propaga en su corazón de enmendar su vida, si más viviere, e de non pecar más, ni ofender a Dios

10 Sobre este particular, ARIÈs (2013, p. 23) recuerda que en el ámbito medieval "A simplicidade familiar era uma das duas características necessárias da morte. A outra era sua publicidade: essa persistirá até o fin do século xıx. O moribundo devia ser o centro de uma reunião". 
ni a sus próximos. Cuarto. Que perdone por amor de Dios a los que le han ofendido e pida perdón de aquellos que él ha injuriado. Quinto, que tome las cosas ajenas. Sexto, que conosca e crea que IhesuChristo murió por salvar a nosotros e por él, e que de otra manera non puede ser salvo, sino por mérito de la su Santa Pasión, por lo qual faga gracias a Dios en quanto e si a estas cosas respondere de buen corazón, señal es que es del número de los que se han de salvar (Ars moriendi, p. 56).

Como señala Eulalio Ferrer (2003), los ars moriendi definen un género de publicaciones que a fines del Medioevo se tornó vastamente popular gracias a los adelantos alcanzados en materia de imprenta y técnicas de grabado. Si bien es cierto que hubo un Ars moriendi original, sus derivaciones no tardaron en formalizar un genuino modelo textual con características propias. Ildefonso Adeva (1992) comenta que dichas expansiones son conocidas bajo el rótulo de Ars moriendi atípicos, que mantienen la materia original, pero se diferencian en su modo de organizarla. A mediados del siglo xv, por ejemplo, circulaba el llamado Art de bien morir, publicado en Valencia, en el que se habla de la necesidad de redactar un testamento espiritual, cuyo fin es declarar que el moribundo habrá de perseverar y morir en la fe de la Iglesia. Estas guías buscaban responder a los tres grandes temores que cercaban el espíritu del cristiano, a saber: el descrédito de la penitencia tardía; la muerte repentina o sin posibilidad de sacramentos; la agonía atormentada. El justo, declaraban, "muere anciano y plácidamente en señal de predestinación" (Adeva 1992, p. 23). Ésta es la forma precisa como fallece don Quijote: "Hallóse el escribano presente, y dijo que nunca había leído en ningún libro de caballerías que algún caballero andante hubiese muerto en su lecho tan sosegadamente y tan cristiano como don Quijote" (II, 74, p. 891). A lo anterior hay que añadir que en estas guías -así como en los documentos trentistas, y por extensión en toda la doctrina cristiana- se destacaban como atributo esencial de Dios el amor y la misericordia, que solían invocarse en oraciones como: "Señor Jesu Cristo, yo tu paraíso demando, no por el valer de mis merecimientos, como sea polvo y ceniza y un mísero pecador, mas en virtud de su sancta pasión, fiuza si no en tu misericordia sola, recíbele en tu amor" (Adeva 1992, p. 18). Así, la misericordia es justamente la primera cualidad que invoca Alonso Quijano tras despertar del prolongado sueño que supuestamente le retri- 
buyó la razón: “¡Bendito sea el poderoso Dios, que tanto bien me ha hecho! En fin, sus misericordias no tienen límite, ni las abrevian los pecados de los hombres" (II, 74, p. 888).

La conjetura de que Cervantes haya tenido en mente estas guías doctrinales no carece, pues, de asidero ${ }^{11}$. En el desenlace todo está dispuesto para que don Quijote conozca una muerte honrosa: la habitación, los asistentes, los rezos, las potestades judiciales y eclesiásticas que avalan la necesidad de confesión y testamento. De confirmarse la gravitación de estas enseñas, convendría examinar de qué modo dichos manuales pueden haber influido en la ideación ejecutada por Cervantes. Para elucidar esta cuestión destacamos dos inquietudes iniciales: una, ¿utilizó los ars moriendi del mismo modo como se valió de los testamentos burlescos, vale decir, con fines irónicos y paródicos?; y otra, ¿aprovechó los perfiles escénicos proporcionados por el género únicamente como marco para conferir dignidad al deceso de su héroe? Para responder estas interrogantes es necesario ahondar en las directrices pedagógicas que incumbían a estas publicaciones. Los ars moriendi poseen como antecedente inmediato el Opusculum tripartitum, conjunto de textos que fue presentado por el canciller de la Universidad de París, Jean Gerson, en el Concilio de Constanza. En este documento se trataban temas como el tránsito de la muerte, la confesión y los pecados capitales. Este tratado germinal tuvo una elaboración posterior que pasó a ser conocida como Tractatus o Speculu martis bene moriendi. Las materias de que se componía eran:

1. Elogio de la muerte.

2. Tentaciones que asaltan al moribundo y modo de superarlas.

3. Preguntas que hay que hacerle al enfermo para reafirmarle en la fe y conseguir el arrepentimiento por sus pecados.

4. Necesidad de imitar la vida de Cristo.

5. Comportamiento que han de adoptar los laicos que acompañan al moribundo: presentación de imágenes sagradas; exhortación a recibir los últimos sacramentos; e incitación a que el interesado otorgue un testamento.

6. Recitación de oraciones por parte de los presentes en favor del expirante (Ruiz García 2001, p. 318).

11 A modo de validación de esta conjetura, cabe destacar que, como afirma Rachel Schmidt (2010), los contenidos retóricos de los Ars se verifican en múltiples momentos de los diálogos sostenidos entre amo y escudero. 
En líneas generales, los ars moriendi pretendían, desde la doctrina de la Iglesia, dar normas de comportamiento y actitudes que convenían tanto al enfermo como a sus deudos, con la finalidad de preparar el mejor espacio posible para la tranquilidad y la elevación espiritual del moribundo. Según muestra Ruiz García, durante la Edad Media este tránsito era considerado un acto público, al que comparecían con carácter de privilegio los seres más cercanos y queridos del agonista. En este evento, añade Ruiz García, se destacaba en términos jurídicos y doctrinales la relevancia de testar:

La reiteración del asunto tenía como corolario subrayar la importancia del testamento. Frente al apego excesivo a los temporalia, objetos, riquezas materiales y seres queridos, se alzaba la obligación de legar los bienes según recomendación de la Iglesia. La mejor solución para obviar esta dificultad era expresar la última voluntad a través de un testamento.

Dado que en el umbral de su muerte el fiel debe rendir cuentas, estos testamentos son detallados en la relación del rito fúnebre y las mandas, según se advierte en las siguientes disposiciones:

1. Exposición de motivos en la que se manifiesta que el autor está en pleno uso de sus facultades mentales ${ }^{12}$.

2. Profesión de fe.

3. Disposición encabezada por una recomendación del alma a Dios (commendatio animae) y seguida de la expresión de las mandas:

a) Elección de sepultura y mortaja.

b) Tipo de entierro y de honras fúnebres.

c) Misas que se deben celebrar.

d) Limosnas y obras pías.

e) Declaración de deudas y formas de cobro.

f) Donación de bienes.

g) Nombramiento de albaceas.

h) Nombramiento de herederos.

i) Cláusulas finales (Ruiz García 2001, p. 343).

12 Deliramento es la palabra que usa Alejo Venegas (2003, p. 102) en su célebre Ars ante el cuadro de juicio deficiente: "Hase, pues, de hacer el testamento en sano juicio, porque después o no habrá lugar de hacerse, o, si se hace, más será deliramento que testamento". 
De estas reglamentaciones -que demuestran la paridad entre el documento religioso y el jurídico ${ }^{13}$ - se desprende la primera sugerencia de que Cervantes parodió el repertorio de los ars. Me refiero al cuarto dictamen de los condicionantes señalados al inicio de este apartado: "Que perdone por amor de Dios a los que le han ofendido e pida perdón de aquellos que él ha injuriado". Esta disposición, que reúne en un solo edicto el valor judicial -utilizado en la exposición de la última manda dictada al escribano (pedir perdón a Avellaneda por haberle inspirado la ejecución de su libro) - con el religioso (disposición de los ars moriendi), comporta un claro signo irónico. No es este indicio, empero, el único que permite atribuir parodia a la sustancia del género en cuestión.

Estos reglamentos prescribían que tanto deudos como asistentes debían observar una actitud solidaria durante la agonía del ser querido para brindarle la paz necesaria en su acceso a la vía trascendente. Teniendo esto en cuenta, la primera reacción de Sancho no condice con el requisito de recogimiento que proporcionaría sosiego al moribundo. La desesperación del escudero ante la postración de su amo quizá sea remedo de la angustia que el Sancho imitativo demuestra en el episodio del melonar, según se advierte en este cotejo:

¡Ay! -respondió Sancho, llorando-: no se muera vuestra merced, señor mío, sino tome mi consejo y viva muchos años, porque la mayor locura que puede hacer un hombre en esta vida es dejarse morir, sin más ni más, sin que nadie le mate, ni otras manos le acaben que las de la melancolía (II, 74, p. 890).

¡O señor! -respondió Sancho-, por el arca de Noé le suplico que no me diga eso de morir, que me hace saltar de los ojos las lágrimas como el puño y me hace el corazón añicos de oírselo, de puro tierno que soy de mío. ¡Desdichada de la madre que me parió! ¿Qué haría después el triste Sancho Panza solo, en tierra ajena, cargado de dos bestias, si vuesa merced muriese en esta batalla? (Fernández de Avellaneda, p. 291).

13 A este respecto, vale tener en cuenta que, además de la paridad formal, existía la paridad sentimental, que envolvía ambas expresiones pre mortem. Ariès (2013, p. 267) lo juzga así: "Apesar de todas as convenções que sofre, o testador expressa, desde meados da Idade Média, um sentimiento próximo daquele das artes moriendi: a consciência de si mesmo, a responsabilidade de seu destino, o direito e o dever de dispor de si, de sua alma, de seu corpo, dos seus bens, a importância atribuída às últimas vontades". 
Según Jiménez (2014), ambas reacciones, en apariencia homólogas, son completamente disímiles en los cauces que toma la historia, pues, a diferencia del Sancho original, en el desenlace el escudero émulo no sólo abandona a su señor, sino que lo olvida. A ello hay que añadir que una cosa es actuar con tales quebrantos en el prólogo de un enfrentamiento armado, como ocurre en el acontecimiento del melonar, y otra muy distinta que se susciten en un espacio que reclama introspección. Si Cervantes efectivamente tuvo en cuenta los ars morien$d i$, el comportamiento que imprimió en su escudero es del todo impertinente.

Entre sus indicaciones, los manuales prescribían el recogimiento, los sacramentos y la oración de los deudos con el fin de garantizar no sólo la paz del agonista, sino también "el espontáneo y pertinaz reconocimiento de la propia indignidad y el recurso suplicante a la misericordia divina" (Adeva 1992, p. 6). Asimismo, recomendaban el alejamiento de cualquier persona que hiciera recordar al moribundo sus pecados. Para favorecer la paz, los ars destacan la importancia de que los asistentes hagan sentir al agonista la proximidad de la muerte y recomiendan que recen con él o por él, en el caso de que las condiciones físicas se lo impidan. Uno de sus incisos declara:

...cada uno debe con grand diligencia e cuidado prever de algund amigo o compañero devoto, idóneo e fiel, el qual le sea e esté presente en su fin e muerte, para que le conseje e conforte en la constancia de la fe, e lo invite e provoque a ver paciencia e devoción, confianza e caridad e perseverança en todas buenas obras, dándole esfuerzo e animando en la agonía e batalla final, e diziendo por él algunas devotas oraciones (apud Gustavo Watson 2013, p. 8).

Watson señala que estas participaciones derivan de la identificación entre el agonista y Cristo, afinidad que comenzó a asentarse en la pedagogía doctrinal desde el siglo XIII. La comparecencia de los asistentes corresponde, pues, a un requisito que presupone los siguientes condicionamientos: respeto, sosiego, empatía, resignación, colaboración y socorro.

No son éstos, sin embargo, los comportamientos que practican los tres beneficiados por el testamento del hidalgo (ama, sobrina y escudero). Si, por una parte, la desesperación inicial de Sancho obsta la paz que debería transmitir a su amo, por otra, la reacción festiva de comer, beber y alegrarse por el bene- 
ficio económico es absolutamente ajena a las orientaciones instituidas por la doctrina del buen morir. Para Iffland (1999), estas palmarias impropiedades de conducta eran eco de una antigua costumbre ritual que, mediante la risa fúnebre, buscaba la prolongación de la vida del moribundo. Creo más bien que dichas impertinencias, que el narrador atribuye a las promesas económicas hechas, son una forma de instarnos a percibir que los ars moriendi, aun cuando probablemente gravitaron en la ideación de la escena final, comparecen deformados por la parodia como efecto de la última relativización de reconocimiento al poder eclesiástico que opera en la novela. Dicho de otro modo, junto con hacernos pensar que hay una complacencia definitiva del poder religioso -cuya doctrina se deja ver en las ordenanzas del comportamiento que rigen a los asistentes del moribundo en su espacio de agonía- se nos muestra la relativización de este mismo poder por medio de la invención de un intersticio paródico que lo ironiza.

A ello hay que añadir que no dejan de ser significativas para la confirmación de un sustrato paródico las palabras que usa el narrador para informarnos del deceso del héroe. Eulalio Ferrer recuerda que entre los escritores de la época era común emplear eufemismos para aludir a la muerte. De ese modo, expresiones como "rendir el alma, cerrar los ojos, ser llamado a juicio, llegar la hora o entrar en la vida perdurable" eran moneda corriente en composiciones de diversos tipos. De entre ellas interesa destacar la elocución dar el espíritu, que, en palabras de Ferrer (2003, p. 82), se trata del "eufemismo prototípico del Renacimiento". Pues bien, éste es precisamente el eufemismo a que recurre Cervantes para noticiar la expiración de su protagonista: dio su espiritu ${ }^{14}$. Lo que nos hace colegir un manejo irónico del recurso eufemístico, y que de cierta forma contribuye a constatar un eje paródico en los preparativos y muerte del hidalgo, es que a renglón seguido el narrador nos confiere esta abrupta explicación: "quiero decir que se murió". Para que un eufemismo opere como tal debiera prescindir de la voz o del concepto que se busca omitir, en este caso la muerte. No es esto lo que hace Cervantes: en lugar de dar validez al eufemismo, lo

14 II, 74, p. 891. No deja de ser sugerente la forma como el narrador de Tirant lo Blanc nos participa del deceso de su héroe: "E dites aquestes paraules reté la noble ànima, restant lo seu bell cos en los braços del duc de Macedònia” (JoANOt MARTORELl 2011, p. 1130). 
hace coexistir con su propia explicación, neutralizándolo y aboliendo el fin retórico a que supuestamente debiera responder.

Con ello, a la secuencia de variables irónicas centradas hasta entonces en las alusiones a géneros legales (testamento) y literarios o editoriales (artes del buen morir), con sus respectivas aplicaciones al contexto cultural y familiar en que se sitúa la acción, Cervantes agrega la ironía retórica vocalizada en el manejo quizás burlesco de un eufemismo consagrado para referir a la muerte, y que se cierra con el epitafio escrito por Sansón Carrasco. Sobre esto último hay que señalar que, continuando con Ferrer, la práctica de los epitafios fue una manera de fundir en una sola forma los ritos fúnebres con las aspiraciones literarias: “...conforme avanzaron los años, los epitafios sepulcrales se olvidaron por completo del lenguaje vulgar y enriquecieron las frases bíblicas con la forma de expresión más sublime, seguramente, que ha creado el ser humano: la poesía”. A lo que el autor agrega:

La intervención de literatos y poetas en los rituales de difuntos provocó que las palabras fúnebres fuesen un objeto de consumo muy codiciado en las altas esferas europeas... No sólo se encargaban epitafios para ser labrados sobre los mármoles de las tumbas, sino también versos creados ex profeso para recordar al difunto, sonetos y odas que muchas veces fueron publicados bajo el título genérico de "Epitafios" (Ferrer 2003, pp. 75-76).

Esta solemnidad, tan solicitada por las ansiedades literarias de la época, es reconocible en la primera estrofa del epitafio concebido por Sansón Carrasco. El segundo y tercer versos de la segunda estrofa nos sitúan directamente en un espacio, si no de ironía, de ostensiva burla: "fue el espantajo y el coco / del mundo, en tal coyuntura" II, 74, p. 892). Recordar al hidalgo con el símil de un espantajo y de un coco que mete miedo a los niños no es precisamente una forma de elevar su dignidad. Creo, sin embargo, que Cervantes no sugirió estos ulteriores guiños de ironía para rebajar la figura del caballero, sino para, nuevamente y por última vez, aprovechar la retórica de un género (el epitafio solemne) con el propósito de parodiarlo mediante sus propios recursos y cerrar así, desde la ficción, el aparato irónico e ideológicamente relativizador que concibió para la muerte de su héroe, antes de asumir su propia voz, trasuntado en el historiador arábigo. 


\section{Conclusiones}

Don Quijote y Sancho son personajes que, gracias al persistente intercambio de visiones y al aprendizaje mutuo, evolucionan de tal manera a lo largo de sus aventuras que los hombres que retornan a la aldea, exhaustos y desorientados, distan enormemente de los entusiastas e ingenuos vecinos que la dejaron por primera vez. Lo alambicado de esta edificación converge en las no menos complejas modulaciones ideológicas que Cervantes transmitió a través de una nutrida serie de entresijos narrativos. El desenlace, que aparece prefigurado en el segundo prólogo, es bien representativo de esta tendencia. Con la muerte del caballero se desata una interrogante de primer orden: ¿el deceso ocurrió bajo el signo de la cordura o la insania? Creo haber demostrado que la postulación de una u otra opción compromete reflexiones ideológicas de notable relevancia. $\mathrm{Si}$, por una parte, la apuesta por la recuperación del juicio hace presuponer la refutación del sistema de creencias que el personaje defendió durante su experiencia quijotesca, por otra, el supuesto del mantenimiento de la locura implica precisamente lo contrario. En el cuadro final se torna evidente no sólo el cuestionamiento del poder seglar mediante la elaboración de un testamento de tenor burlesco, sino también, y de manera más oblicua, pero no menos sustancial, de la institución religiosa, valiéndose de una probable parodia dirigida a los ritos católicos del buen morir.

Esta relativización del poder religioso no es imprevista, pues condice coherentemente con la posición que don Quijote ha sostenido durante toda la novela respecto a la Iglesia. Para Cervantes, las creencias trascendentales no podían quedar reducidas al mero cumplimiento de ritos o ceremonias como lo eran, por ejemplo, las conducciones prescritas en los ars moriendi desde su eclosión medieval. Como apunta Pérez Martínez (2012), Cervantes fue ante todo un cristiano sincero, pero inconformista y contestatario, que diagnosticó el estado de un cristianismo desvitalizado, preocupado únicamente de su aparato formal.

Cuando revisamos las posibles motivaciones que tuvo Cervantes para la ideación de su obra capital advertimos que un buen número de éstas convergía en preocupaciones de tipo social y se asentaba en un interés por las complejidades de la naturaleza y experiencia humanas. Las representaciones sociales transmitidas por Cervantes no pueden comprenderse como categorizaciones absolutas. Si en algunas ocasiones parece 
adherirse a las enseñas de poder, en otras deja intuir a un escritor que, con recursos de altísima cautela, como la ironía o la crítica subyacente, cuestionó la validez del sistema ideológico que amparaba a las instituciones seglares y religiosas. Como ha enunciado Ignacio Padilla (2005, p. 104) a propósito de las instituciones que aspiraron a representar un orden trascendente, don Quijote "fue tanto su más acre crítico como uno de sus más conspicuos abanderados".

Los cuestionamientos cervantinos del orden de cosas y sus expresiones materiales e institucionales se vocalizan con tal sutileza que es competencia del lector dilucidar los intersticios narrativos por donde atraviesan los juicios del autor sobre el mundo que lo vio venir.

\section{REFERENCIAS}

Adeva Martín, Ildeffonso 1992. "Cómo se preparaban para la muerte los españoles a finales del siglo Xv", Anuario de Historia de la Iglesia, 1, pp. 113138, http:/ / dialnet. unirioja.es / servlet/ articulo?codigo=1204296 [consultado en diciembre de 2014].

Ariès, Philippe 2013. O homem diante da morte, Editora Unesp, São Paulo.

Ars moriendi - Arte de bien morir y Breve confesionario 1999. Ed. Francisco Gago, Medio Maravedí, Barcelona.

Cervantes, Miguel de 2005. El ingenioso Hidalgo don Quijote de La Mancha, Editorial Tomo, México.

Collo, Carlo 1995. Reconciliación y penitencia. Comprender, vivir, celebrar, Eds. San Pablo, Madrid, http:// zarazua.wordpress.com/ [consultado el 11 de noviembre de 2014].

Fernández de Avellaneda, Alonso 2005. El ingenioso Hidalgo don Quijote de La Mancha. Ed. Luis Gómez Canseco, Juventud, Barcelona.

Ferrer, Eulalio 2003. El lenguaje de la inmortalidad. Pompas fúnebres, Fondo de Cultura Económica, México.

Franco, Ricardo 1972. "La confesión en el Concilio de Trento: exégesis e interpretación”, Selecciones de Teología, 41, http:/ / www.seleccionesdeteologia. net/ [consultado el 11 de noviembre de 2014].

Frenk, Margit 2013. Cuatro ensayos sobre el Quijote, Fondo de Cultura Económica, México.

IfFland, James 1999. De fiestas y aguafiestas: risa, locura e ideología en Cervantes y Avellaneda, Iberoamericana, Madrid.

Martín Jiménez, Alfonso 2014. Las dos segundas partes del Quijote, Repositorio Documental de la Universidad de Valladolid, Valladolid, http: / uvadoc.uva.es/ handle/10324/ 7092 [consultado en noviembre de 2014].

Martorell, JoAnot 2011. Tirant lo Blanc, Organisme Autònom per a la Societat de la Informació de la Diputació, Tarragona. 
Padilla, Ignacio 2005. El diablo y Cervantes, Fondo de Cultura Económica, México.

Pérez Martínez, Ángel 2012. El Quijote y su idea de virtud, CSIC-Instituto de Lengua, Literatura y Antropología, Madrid.

Rodríguez Molina, José 2008. "La confesión auricular. Origen y desarrollo histórico", Gazeta de Antropología, 24, 1, http:/ / www.ugr.es/ pwlac/ G24_11Jose_Rodriguez_Molina.html [consultado el 11 de noviembre de 2014].

Rubio Árquez, Marcial 2012. "De la literatura popular a la parodia textual: el testamento de don Quijote", eHumanista, 21, pp. 305-335, http:/ / www. ehumanista.ucsb.edu/volumes/.../ 10\%20ehumanista21. rubio. pdf [consultado el 8 de octubre de 2014].

Ruiz García, Elisa 2001. "El Ars moriendi: una preparación para el tránsito", en IX Jornadas científicas sobre documentación: la muerte y sus testimonios escritos, Universidad Complutense, Madrid, pp. 315-344, http://www.ucm. es/ data/ cont/docs/446-2013-08-22-10_ruiz\%20garcia.pdf. [consultado el 1 de diciembre de 2014].

SchmidT, RACHel 2010. "La praxis y la parodia del discurso del Ars moriendi en el Quijote de 1615”, Anales Cervantinos, 42, pp. 117-130.

VAn Dijk, Teun 1999. Ideología. Un enfoque multidisciplinario, Gedisa, Barcelona.

Venegas, Alejo 2003. "Agonía del tránsito de la muerte", en Artes de bien morir. Ars moriendi de la Edad media y del Siglo de Oro. Ed. Antonio Rey Hazas, Ediciones Lengua de Trapo, Madrid.

Watson, Gustavo 2013. "El Ars moriendi del siglo xv, el culto y algunas formas concretas de piedad en la liturgia de los siglos XIV y Xv", http:/ / pt.scribd.com/ doc/243379524/trabajo-de-watson-docx [consultado el 3 de diciembre de 2014]. 